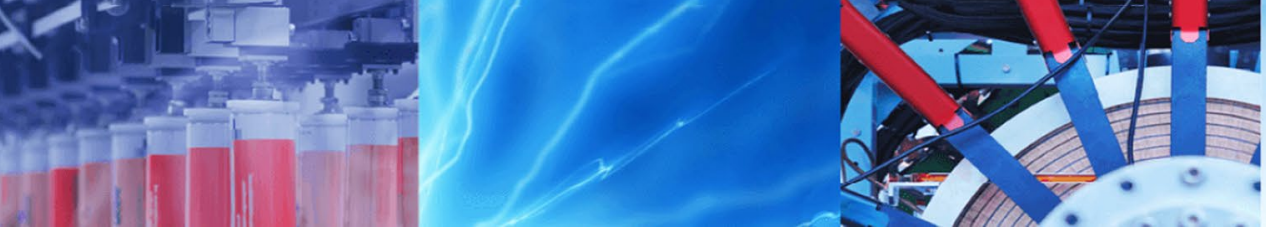

Research Article

\title{
Preparation and characterization of dithiol-modified graphene oxide nanosheets reinforced alginate nanocomposite as bone scaffold
}

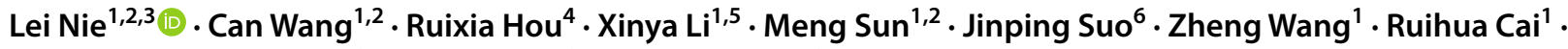

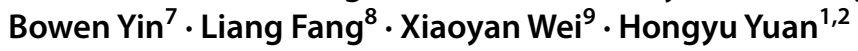

(c) Springer Nature Switzerland AG 2019

\begin{abstract}
Porous graphene oxide (GO) nanocomposite as scaffold has attracted increasing attention in bone tissue engineering recently. In this study, GO nanosheets was modified by 2,2'-(ethylenedioxy)-diethnethiol (EDDET), and dithiol-modified GO (DT-GO) nanosheets were obtained. The results confirmed that GO nanosheets were cross-linked by EDDET, meanwhile, the distance between GO layers reduced after modification. Next, DT-GO nanosheets were further incorporated into alginate hydrogels to fabricate DT-GO/alginate (DT-GA) nanocomposite as scaffold. The prepared DT-GA nanocomposite behaved the laminar network morphology with interconnected porous structure confirmed by SEM analysis. In addition, the DT-GA nanocomposite with the concentration of DT-GO nanosheets at $16.7 \%$ showed the highest porosity value and lowest compressive strength. Furthermore, the bone marrow derived mesenchymal stem cells (BMSCs) showed a good proliferation on DT-GA nanocomposite, demonstrated that prepared nanocomposite had a good cytocompatibility, which was identified by CCK-8 assay and fluorescent microscopy images. Lastly, ALP activity analysis certified that BMSCs seeded on DT-GA nanocomposite could differentiate into osteoblastic phenotype. Above results suggest that the dithiol-modified GO/alginate nanocomposite has the potential to be applied in bone tissue engineering.
\end{abstract}

Keywords Graphene oxide · Alginate - Nanocomposite · Bone scaffold · Cytocompatibility · Bone tissue engineering

\section{Introduction}

The autologous tissue transplantation was a traditional method for treating bone defects, but limited for source and additional injuries [1, 2]. Based on three-dimensional (3D) porous scaffold combined with cells and bioactive agents, bone tissue engineering has showed many priorities for bone regeneration in several reports $[3,4]$. As the cytoskeleton, the scaffold should possess a good biocompatibility and interconnected structure for supporting cells attachment and proliferation [5]. In addition, the mechanical strength, related with architecture and chemical composition, was an important criterion for applying scaffold in load-bearing (cortical bone) or

Electronic supplementary material The online version of this article (https://doi.org/10.1007/s42452-019-0581-6) contains supplementary material, which is available to authorized users.

\footnotetext{
$\triangle$ Lei Nie, nieleifu@yahoo.com; nielei@xynu.edu.cn; $\bowtie$ Ruixia Hou, hourx130@163.com | ${ }^{1}$ College of Life Sciences, Xinyang Normal University (XYNU), Xinyang 464000, People's Republic of China. ${ }^{2}$ Institute for Conservation and Utilization of Agro-Bioresources in Dabie Mountains, Xinyang 464000, People's Republic of China. ${ }^{3}$ Department of Mechanical Engineering, Member of Flanders Make, KU Leuven (Catholic University of Leuven), Louvain 3001, Belgium. ${ }^{4}$ Medical School of Ningbo University, Ningbo 315211, People's Republic of China. ${ }^{5}$ School of Life Sciences, University of Science and Technology of China, Hefei 230026, People's Republic of China. ${ }^{6}$ State Key Laboratory of Mould Technology, College of Materials Science and Engineering, Huazhong University of Science and Technology, Wuhan 430074, People's Republic of China. ${ }^{7}$ College of Chemistry and Chemical Engineering, Xinyang Normal University, Xinyang 464000, People's Republic of China. ${ }^{8}$ Collaborative Innovation Center, Xinyang Normal University, Xinyang 464000, People's Republic of China. ${ }^{9}$ Max Planck Institute for Molecular Genetics, Ihnestraße 63-73, 14195 Berlin, Germany.
} 
unload-bearing (cancellous bone) bone replacement [6]. In recent years, many researchers have been focusing on how to further improve the mechanical properties of scaffolds. For example, nanocomposite scaffold, 3D printed composites, dual-network composites, etc., which all showed improved mechanical properties [7-10]. Thereinto, the graphene showed promising potentials in bone tissue engineering, due to the large specific surface area and superior mechanical strength. Some studies have revealed that the stem cells seeded on graphene-based scaffolds could differentiate into osteoblasts [11, 12], furthermore, graphene-coated materials could accelerate the osteogenesis of human mesenchymal stem cells (hBMCs) [13].

As we all known, the graphene is a two-dimensional carbon nanomaterial with a honeycomb lattice composed of carbon atoms and $\mathrm{sp}^{2}$ hybrid orbitals $[14,15]$. During the last decade, graphene-derived materials, such as graphene oxide (GO), carbon nanotubes, and three-dimensional graphene foams, and so on, have been extensively explored for biomedical applications [16-19]. Among them, GO is a laminated material obtained by oxidation of graphite, and GO has higher specific surface area and higher mechanical strength comparing to graphene [20]. Furthermore, GO showed a good interface with hydrophilic matrix through hydrogen bonds due to oxygen-containing functional groups, including hydroxyl group, epoxy functional group, carbonyl group, carboxyl group, etc., and biocompatibility and mechanical property of GO composites could be further improved [21, 22]. The carboxyl groups of GO could covalent linked with the amine groups of chitosan to obtain hybrid $\mathrm{GO} /$ chitosan composite for stimulating the osteoblasts growth, as reported by Depan et al. [23]. The hydroxyl groups in GO also could interact with some polymer contained carbonyl groups by intermolecular hydrogen bonds, for examples, poly( $\varepsilon$-caprolactone) ( $P C L)$ $[24,25]$. GO have been exploited as cross-linker or filler in polymer chains to produce functional porous scaffolds. Such as, the organic/inorganic composite with interpenetrating network could be fabricated by casting GO suspension into polymer chains [26]. Our previous experiences on porous composite composed of poly(vinyl alcohol) and $\mathrm{GO}$ confirmed that $\mathrm{GO}$ could improve the mechanical properties, however, the poor cytocompatibility limited its application scope in tissue engineering [27]. The natural biopolymers, such as gelatin, chitosan, glucose oxidase, alginate, konjac glucomannan, carboxymethylcellulose, etc., have attracted great interests in GO-based composite because of excellent biocompatibility and biodegradability [28-33].

Alginate is a nested linear polysaccharide with homopolymeric blocks of (1-4) linked $\beta$-D-mannuronate $(M)$ and $C-5$ epimer $\alpha-L-g u l u r o n a t e ~(G)$. Alginate has been widely used in tissue engineering fields on account of rich production, low cost, biological compatibility, and abundant functional groups [34]. However, the poor mechanical strength of alginate restrained its application as bone substitute. Some studies reported that alginate could compound with other polymers, including chitosan, cellulose, and so on, though the mechanical strength was improved by such blending method, poor stability and biological performance were exist still $[35,36]$. It was known that the numerous functional groups (e.g. hydroxyl groups and carboxyl groups) in the basal planes and the edges of GO nanosheets could readily form interfacial interaction as hydrogen bonds with hanging hydroxyl groups of alginate chain. The chemical modification on GO nanosheets could ameliorate the mechanical properties and biological functions of $\mathrm{GO}$ composites. The $\mathrm{GO}$ nanosheets were modified by using small molecules could influence the morphology, as well as the physicochemical properties. Owen C. Compton et al. [37] reported that the electrically conductive "alkylated" GO paper could be prepared by chemical reduction of amine modified GO. In addition, the $\mathrm{GO}$ nanosheets could be modified by using the divalent metals ions, which interacting with some functional groups of GO, then the mechanical property was significantly improved. Khademhosseini et al. [38] used 3-(trimethoxysilyl) propyl methacrylate (TMSPMA) to obtain methacrylated GO (MeGO), and covalently incorporated with methacrylated gelatin (GelMA), such mechanical properties could be controlled by the concentration of MeGO. Nonetheless, the mechanical strength of composite is not only depended on the shape of GO nanosheets, but also depended on the distance of GO nanosheet layers. Here, 2,2'-(ethylenedioxy)-diethnethiol (EDDET) was used as a cross-linker between GO nanosheets. EDDET is a biomolecular molecule containing sulfhydryl at both ends $[27,39]$.Because the layers distance and morphology of GO changed, the pore morphology and mechanical properties of GO-based nanocomposites could be further influenced.

In this paper, the dithiol-modified GO (DT-GO) was obtained by modifying GO with EDDET by using a modified method according to our previous work [27]. DT-GO nanosheets were composited into alginate to produce porous DT-GO/alginate (DT-GA) nanocomposite, as shown in Scheme 1. At the same time, the graphene oxide/alginate (GA) nanocomposite was prepared by using the same method as comparison. The physicochemical properties of prepared nanocomposites were investigated by FT-IR, SEM and EDX. In addition, the porosity and compressive strengths of nanocomposites were measured. Finally, the proliferation and osteoblastic phenotype differentiation of bone marrow derived mesenchymal stem cells (BMSCs) seeded on nanocomposites were evaluated by CCK- 8 assay, fluorescent microscopy images and ALP activity. 
Scheme 1 Schematic illustration of dithiol-modified graphene oxide (DT-GO) nanosheets preparation and DT-GO/alginate (DT-GA) nanocomposite preparation. a 2,2'-(ethylenedioxy)diethnethiol (EDDET) was used to modify graphene oxide to change the distances between nanosheets and GO morphology; b DT-GO nanosheets were composited into alginate solution, then DT-GO/alginate (DT-GA) nanocomposite with aligned pore structure was obtained by freeze-drying method a

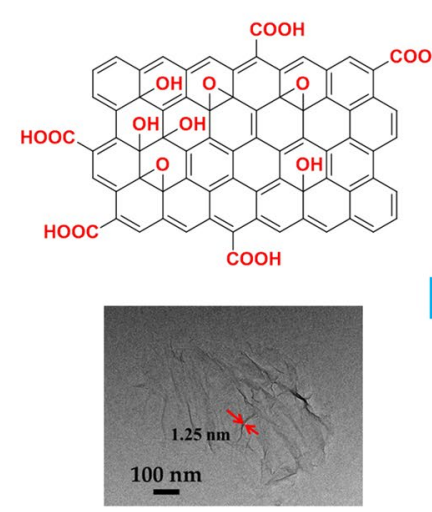

GO Nanosheets

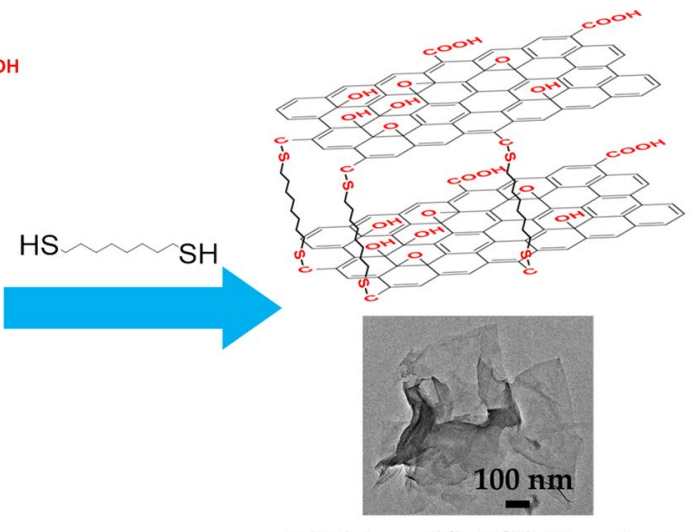

Dithiol-modified GO Nanosheets b

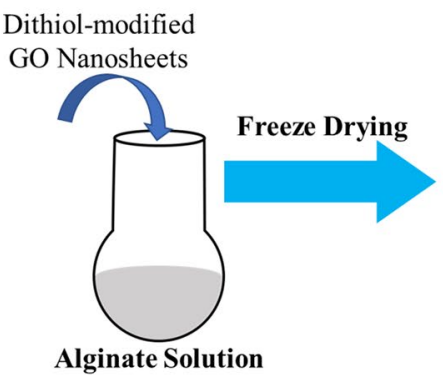

\section{Materials and methods}

\subsection{Materials}

Graphite was obtained from Qingdao Henglide graphite Co. Ltd., Sodium nitrate $\left(\mathrm{NaNO}_{3}, \mathrm{ACS}, 99.0 \%\right)$ and potassium permanganate $\left(\mathrm{KMnO}_{4}, \mathrm{AR}\right)$ were obtained from Aladdin Co., Ltd. Hydrogen peroxide $\left(\mathrm{H}_{2} \mathrm{O}_{2}, \mathrm{GR}, 30 \%\right)$, concentrated sulfuric acid $\left(\mathrm{H}_{2} \mathrm{SO}_{4}, 98 \%, \mathrm{GR}\right)$ and hydrochloric acid $(\mathrm{HCl}, 36.5 \mathrm{wt} \%, \mathrm{AR})$ were purchased from SinoPharm Group Co., Ltd. Sodium alginate $\left(\mathrm{C}_{5} \mathrm{H}_{7} \mathrm{O}_{4} \mathrm{COONa}\right)$ was obtained from Macklin Chemical Reagent Co., Ltd. 2,2'-(Ethylenedioxy)-diethnethiol (EDDET) was obtained from Sigma-Aldrich Chemical Reagent Co., Ltd. Agarose powder $\left(\mathrm{C}_{10} \mathrm{H}_{15} \mathrm{~N}_{3} \mathrm{O}_{3}\right.$, purity degree $\left.\sim 100 \%\right)$ were purchased from SinoPharm Chemical Reagent Co., Ltd. All other chemicals were purchased from China National Medicines Corporation Co., Ltd (analytical grade). All chemicals were used without further purification.

\subsection{Synthesis of graphene oxide (GO) nanosheets}

GO nanosheets were prepared by using an improved Hummers method according to previous report [40]. First, $23 \mathrm{~mL}$ of concentrated sulfuric acid was added to the flask, $1 \mathrm{~g}$ of graphite powder was added, and the flask was sealed and put it at $0-4{ }^{\circ} \mathrm{C}$ in the ice water bath. Then, $1.5 \mathrm{~g}$ of sodium nitrate was added to above flask and stirred slowly for $2 \mathrm{~h}$. After stirring well, $3 \mathrm{~g}$ of potassium permanganate was added into the mixture slowly and continued stirring for $2 \mathrm{~h}$. Then, the water bath temperature was increased to $35^{\circ} \mathrm{C}$, and maintained heating for $4 \mathrm{~h}$. Once again, the water bath was heated to $90^{\circ} \mathrm{C}$, and $46 \mathrm{~mL}$ of deionized water was slowly dropped into the flask, continued to stir for $15 \mathrm{~min}$. Then, the hydrogen peroxide was added into the mixture drop by drop until the solution does not bubble up during stirring, and continued stirring for 15 min again. Next, the mixture was filtered through a brinell, and cleaned repeatedly with $5 \%$ hydrochloric acid solution to remove the unreacted impurities. Finally, the solid was washed by hydrochloric acid and centrifuged repeatedly with deionized water until the graphite oxide dispersion was neutral and the supernatant reacted with barium chloride without white precipitation, and collected GO solids were freeze-dried and GO nanosheets powder was obtained.

\subsection{Synthesis of dithiol modified graphite oxide (DT-GO) nanosheets}

The $0.01 \mathrm{~g} / \mathrm{mL}$ of GO solution was prepared by dissolving as-prepared GO powder $(1 \mathrm{~g})$ into deionized water 
$(100 \mathrm{~mL})$ in a flask containing. A certain amount of EDDET $(2.58 \mathrm{mM})$ was added to the $\mathrm{GO}$ solution, under continuous magnetic stirring at $60^{\circ} \mathrm{C}$, resulting in a homogeneous black dispersion in $30 \mathrm{~min}$. The heating time was prolonged to $2 \mathrm{~h}$ until cooling to room temperature. The DT-GO solution was obtained. The DT-GO powder was also obtained by vacuum-drying machine at $30^{\circ} \mathrm{C}$ for 2 days.

\subsection{Characterizations of GO and DT-GO}

\subsubsection{FT-IR analysis of GO and DT-GO}

The GO and DT-GO nanosheets were mixed with $\mathrm{KBr}$ powders, grinded and pressed into thin sections respectively, and the $\mathrm{KBr}$ sheets were tested as blank controls. Fourierinfrared spectroscopy (FT-IR, ThermoFisher, Nicolelis5) was used to analyze the distribution of different groups of $\mathrm{GO}$ and DT-GO, so as to help confirm the success of DT-GO synthesis.

\subsubsection{XRD analysis of GO and DT-GO}

The prepared samples were grinded into powders in agate mortar, and then sprinkled the sample powder as evenly as possible into the sample preparation box of window, with a small spatula knife edge gently chop tight, make sure the powder booth well stacked inside the hole. Then, the powders were compacted gently with a small spatula, and finished with a razor blade (or slide fracture) peel the redundant bulge powders to get a very flat the plane of the sample powders. A Rigaku Smartlab $9 \mathrm{~kW}$ diffractometer, operating at $45 \mathrm{kV}$ and $200 \mathrm{~mA}$ with Cu Ka radiation $(\lambda=1.5406 \AA)$ and a spinning sample holder, was used to collect the X-ray powder diffraction (XRD) patterns.

\subsubsection{XPS analysis of GO and DT-GO}

A small piece of double-sided adhesive (about $2 \mathrm{~mm} \times 2 \mathrm{~mm}$ ) was attached to the aluminum foil, and the powder sample was sprinkled evenly on the tape. The powder covered the whole tape evenly. Then, the aluminum foil was fold and placed on the tablet. Rotated the press to the bottom, rotated the knob to the right, tightened it, then applied pressure to about $6 \mathrm{MPa}$. Kept pressure up to 1 min after unloading (turn left turn knob). Finally, the sample was removed (ensured that the aluminum foil was peeled) and was placed in a clean sealing bag. The X-ray Photoelectron Spectroscopy analyzer (XPS, K-Alpha $0.05 \mathrm{eV}$, Thermo Scientific) was used to test the processed samples to obtain the elements composition of GO and DT-GO.
Table 1 The designation of dithiol-modified graphene oxide/alginate (DT-GA) nanocomposites

\begin{tabular}{lllll}
\hline Nanocomposites & DT-GA1 & DT-GA2 & DT-GA3 & DT-GA4 \\
\hline SA powder & $0.10 \mathrm{~g}$ & $0.12 \mathrm{~g}$ & $0.14 \mathrm{~g}$ & $0.16 \mathrm{~g}$ \\
DT-GO solution $^{\mathrm{a}}$ & $2 \mathrm{~mL}$ & $2 \mathrm{~mL}$ & $2 \mathrm{~mL}$ & $2 \mathrm{~mL}$ \\
\hline
\end{tabular}

${ }^{\text {a }}$ The concentration of DT-GO solution is $0.01 \mathrm{~g} / \mathrm{mL}$

Table 2 The designation of graphene oxide/alginate (GA) nanocomposites

\begin{tabular}{lllll}
\hline Nanocomposites & GA1 & GA2 & GA3 & GA4 \\
\hline SA powder & $0.10 \mathrm{~g}$ & $0.12 \mathrm{~g}$ & $0.14 \mathrm{~g}$ & $0.16 \mathrm{~g}$ \\
GO solution $^{\mathrm{a}}$ & $2 \mathrm{~mL}$ & $2 \mathrm{~mL}$ & $2 \mathrm{~mL}$ & $2 \mathrm{~mL}$ \\
\hline
\end{tabular}

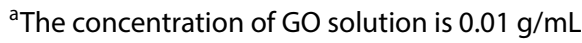

\subsubsection{TEM analysis of GO and DT-GO}

The GO and DT-GO samples powders were dissolved in Millipore water, and sonicated for $2 \mathrm{~h}$, then, the copper grid was dipped into sample solutions and dried under infrared lamp. The Transmission Electron Microscope (TEM, Tecnai G2 F20) was used to analysis the morphology of GO and DT-GO nanosheets.

\subsection{Synthesis of dithiol-modified graphene oxide/ alginate (DT-GA) and graphene oxide/alginate (GA) nanocomposites}

The DT-GA nanocomposite was prepared as below. Briefly, $2 \mathrm{~mL}$ of DT-GO solution $(0.01 \mathrm{~g} / \mathrm{mL})$ was measured and placed in a glass tube. Then, the sodium alginate powder was added and stirred for $24 \mathrm{~h}$ at room temperature to obtain hydrogel. Finally, the prepared hydrogel was placed in freezer $\left(-20^{\circ} \mathrm{C}\right)$ for $24 \mathrm{~h}$ at least, then freeze-dried for $48 \mathrm{~h}$ to get DT-GA nanocomposite. The designation of DT-GA was shown in Table 1, according to different weight of used sodium alginate. At the same time, the GA nanocomposites were prepared by using the same method, and the designation was shown in Table 2.

\subsection{Physicochemical characteristics of GA and DT-GA nanocomposites}

\subsubsection{FT-IR analysis}

The Fourier-infrared spectroscopy (FT-IR, ThermoFisher, Nicolelis5) was used to characterize the presence of specific chemical groups in GA and DT-GA nanocomposites, the FT-IR spectra range was between 4000 and $500 \mathrm{~cm}^{-1}$, with using attenuated total reflectance (ATR) technique. 


\subsubsection{SEM analysis}

The cross-section of the porous prepared nanocomposite was investigated by Cold Field Scanning Electron Microscope (SEM, S-4800, Hitachi, Japan). Before testing, the samples were freeze-dried and broken off in liquid nitrogen environment, then the samples were coated with platinum $(\mathrm{Pt})$ to prevent imaging artifacts from electrical charging. The Energy Dispersive X-ray Spectroscopy (EDX) was operated during capturing the SEM images. The pore size could be calculated from SEM images by using ImageJ software.

\subsubsection{Porosity analysis}

The porosity of prepared nanocomposite was measured by using liquid displacement method. The dried nanocomposite was soaked in a known volume $\left(V_{1}\right)$ of ethanol. The total volume of the nanocomposite and solution was measured as $V_{2}$. After $30 \mathrm{~min}$, the nanocomposite was removed and the remaining ethanol volume was measured as $V_{3}$. Then the porosity $(\mathrm{P})$ was calculated using the following Eq. (1):

$P=\frac{V_{1}-V_{2}}{V_{2}-V_{3}} \times 100 \%$

\subsubsection{Mechanical properties analysis}

The compression performance of the prepared nanocomposite was tested by using an electromechanical universal testing machine (CMT4103, China) at a crosshead contraction speed of $2 \mathrm{~mm}$ per minute. The compressive offset yield stress was determined from the stress-strain curve at a $2 \%$ strain.

\subsection{In vitro studies}

\subsubsection{Cell culture}

Bone marrow derived mesenchymal stem cells (BMSCs, ATCC $^{\circ}$ PCS-500-012 ${ }^{\mathrm{TM}}$ ) was used for cytocompatibility of scaffolds evaluation. According to ATCC instructions, BMSCs were grown in Dulbecco's modified Eagle's medium (DMEM) supplemented with $10 \%$ fetal bovine serum, $100 \mathrm{U} \mathrm{mL}^{-1}$ penicillin, and $100 \mu \mathrm{g} \mathrm{mL}^{-1}$ streptomycin (all purchased from Gibco USA) under a humidified atmosphere of $95 \%$ air and $5 \% \mathrm{CO}_{2}$ at $37^{\circ} \mathrm{C}$. The medium was changed every 2 days. When the BMSCs reached confluence, cells were removed by using $0.25 \%$
trypsin-EDTA (Sigma-Aldrich), centrifuged and re-suspended in the DMEM medium.

\subsubsection{Cell counting kit-8 (CCK-8) analysis}

The prepared nanocomposites were soaked by $75 \%$ alcohol for $24 \mathrm{~h}$, then nanocomposites were transferred to cell culture room through UV window, and the alcohol was sucked out on ultra-clean working table. The alcohol inside the scaffolds was replaced by PBS, and this operation was repeated every one hour at least 3 times. Then, a $10 \mu \mathrm{L}$ (about $1 \times 10^{5}$ cells) of cell suspension was dipped onto the surface of nanocomposites. The nanocomposites were washed twice with PBS after $2 \mathrm{~h}$ to make sure the cells were adhered to the nanocomposites. Next, $1 \mathrm{~mL}$ of DMEM medium was added. The nanocomposites were maintained at $37{ }^{\circ} \mathrm{C}$ under a $5 \% \mathrm{CO}_{2}$ humidified atmosphere of $95 \%$ air, the medium was changed every 2-3 days (depending on the color of DMEM, if color changed, the medium was changed). The cell counting kit-8 (CCK-8, Dojindo Molecular Technologies, Inc) was used to investigate the cell attachment and viable cells level. The nanocomposites at different days were treated with CCK-8 solution for $2 \mathrm{~h}, 100 \mu \mathrm{L}$ of each sample was transferred to a 96-well plate, and measured at $570 \mathrm{~nm}$ by a micro-plate reader (SpectraMax 190, Molecular Devices, USA).

\subsubsection{Alkaline phosphatase (ALP) assay}

The osteoblastic differentiation of prepared engineered nanocomposites as scaffold was scaled by ALP activity. The nanocomposites with cells adhered were soaked in $300 \mu \mathrm{L}$ lysis buffer and sonicated in an ice bath for 1 min to get cell lysates. Then, a Quant-iT ${ }^{T M}$ protein assay kit (Invitrogen, USA) was used to quantify cell lysates. The cell lysates were incubated in sodium $\rho$-nitrophenyl-2-phosphate at $37^{\circ} \mathrm{C}$ for $1 \mathrm{~h}$, and $1 \mathrm{M} \mathrm{NaOH}$ was added into to neutralize the reaction, the amount of $\rho$-nitrophenol released in solution was measured by light absorbance at $405 \mathrm{~nm}$ to estimate ALP activity.

\subsubsection{Fluorescent microscopy analysis}

After the nanocomposites cultured with BMSCs for specific days, the nanocomposites were removed from the cell medium and washed with PBS 3 times, then fixed with $2 \%$ glutaraldehyde for $12 \mathrm{~h}$. The nanocomposites were washed with PBS 3 times again, soaked in $0.1 \%$ Triton X-100 for 10 min and washed with PBS again. Next, the BMSCs on the nanocomposites were blocked with $1 \%$ bovine serum albumin for $30 \mathrm{~min}$, subsequently stained with $100 \mu \mathrm{g} / \mathrm{mL}$ phalloidin-FITC (Invitrogen, USA) under dark environment for $1 \mathrm{~h}$, then washed with PBS 3 times. Finally, $10 \mu \mathrm{g} / \mathrm{mL}$ 
4',6-diamidino-2-phenylindole (DAPI, Thermo Scientific ${ }^{\mathrm{TM}}$ ) was added in dark for $5 \mathrm{~min}$. The nanocomposites were washed with PBS three times again. Confocal Laser Scanning Microscope (CLSM, Leica TCS SP5 II, Germany) was used to obtain fluorescent images.

\subsection{Statistical analysis}

Unless indicated, data were given as mean $\pm \operatorname{SD}(n=5)$. Statistics analysis of obtained results was carried out using a one-way analysis of variance (one-way ANOVA), and significance reported at a $p$ value of $<0.05$ for $95 \%$ confidence. All statistical calculations were performed using GraphPad Prism software.
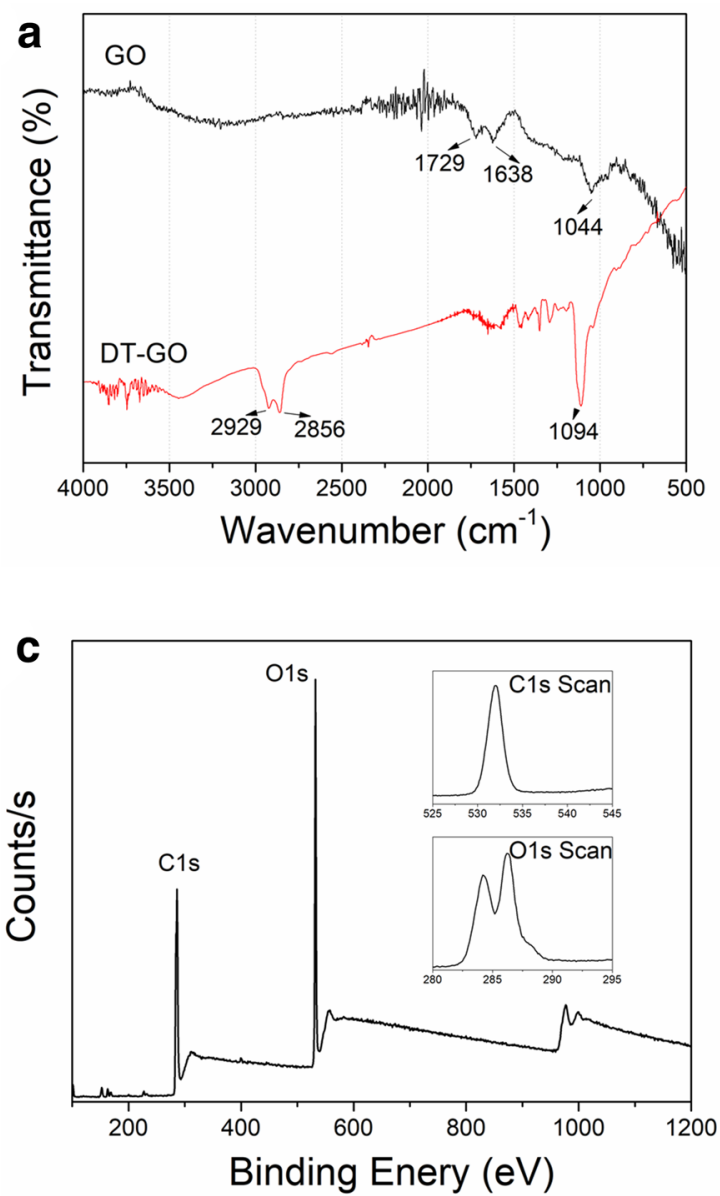

Fig. 1 Physicochemical properties of prepared GO and DT-GO nanosheets. a FT-IR spectra of GO and DT-GO; $\mathbf{b}$ XRD spectra of $\mathrm{GO}$ and DT-GO; c XPS spectrum of GO, the insets showed the $\mathrm{C} 1 \mathrm{~s}$

\section{Results}

\subsection{Characteristics of prepared GO and DT-GO nanosheets}

FT-IR was first used to examine the chemical modification of $G O$ with dithiol chemical (EDDET), as shown in Fig. 1 a. The broad band centered at $3400 \mathrm{~cm}^{-1}$ was due to $\mathrm{O}-\mathrm{H}$ groups of $\mathrm{GO}$, the band at $1729 \mathrm{~cm}^{-1}$ was due to $\mathrm{C}=\mathrm{O}$ groups, in addition, other characteristic vibrations of $\mathrm{GO}$, such as, the $\mathrm{O}-\mathrm{H}$ deformation peak at $1390 \mathrm{~cm}^{-1}$, and the $\mathrm{C}-\mathrm{O}$ stretching peak at $1044 \mathrm{~cm}^{-1}$, confirmed the successful synthesis of $G O$ here. However, the band at $3400 \mathrm{~cm}^{-1}$ of $\mathrm{GO}$ was dramatically depressed after the modification of EDDET on the surface of GO, and the epoxy $\mathrm{C}-\mathrm{O}$ bands at $1044 \mathrm{~cm}^{-1}$ were also weakened for DT-GO. Together with the methylene peaks at $2929 \mathrm{~cm}^{-1}$ and $2856 \mathrm{~cm}^{-1}$, and the C-S band at $782 \mathrm{~cm}^{-1}$ from DT-GO, confirmed that the EDDET with dithiol groups were successfully modified on
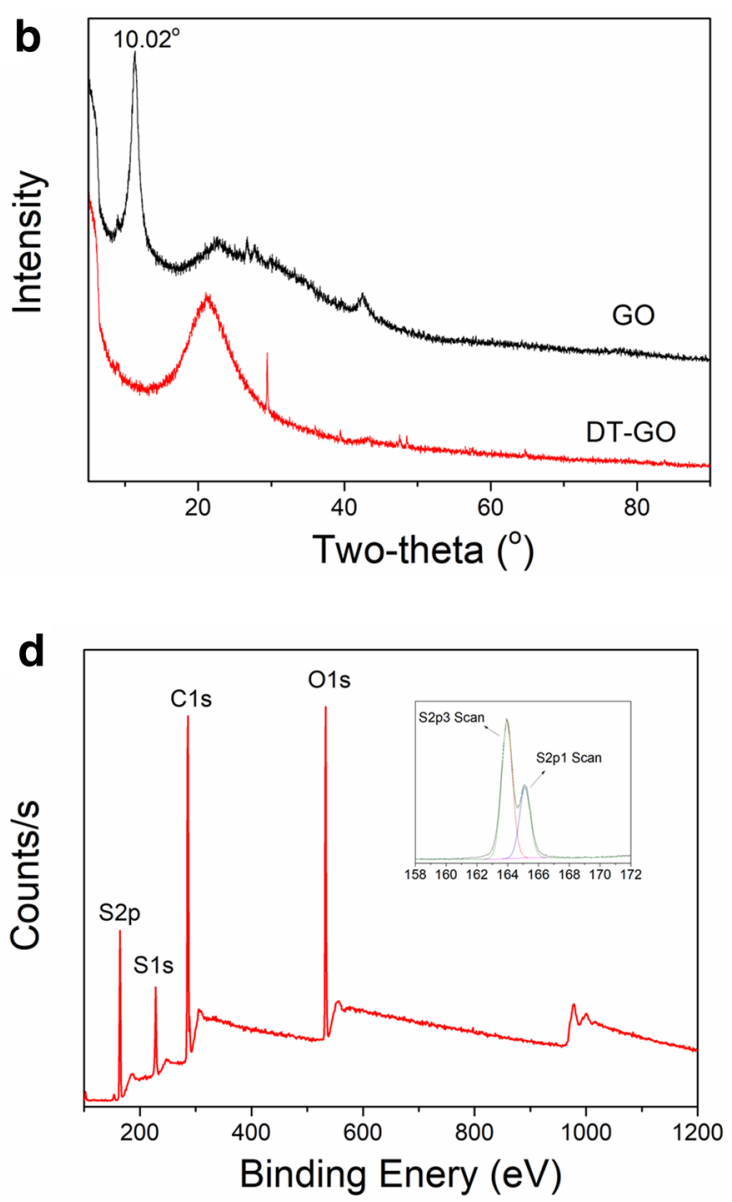

and O1s scanning respectively; $\mathbf{d}$ XPS spectrum of DT-GO, the inset showed the S2p1 and S2p3 scanning, confirmed the formation of C-S bond 
the GO. X-ray diffraction (XRD) was also used to analysis the composition of GO and DT-GO, the results were shown in Fig. 1b. Regarding the Bragg's law, the XRD spectrum of GO showed an evident sharp peak at $2 \theta=10.02^{\circ}$, corresponding to a $d$-spacing of $0.87 \mathrm{~nm}$, which mainly due to the inter-lamellar water trapped between $\mathrm{GO}$ nanosheet. The peak shifted to $2 \theta=21.42^{\circ}$ for DT-GO, indicated the distance between $\mathrm{GO}$ nanosheets decreased to $0.08 \mathrm{~nm}$. The significant reduced layer distance further influenced the morphology and physicochemical properties of hybrid materials while the DT-GO dispersed into polymer strains. To further understand the dithiol groups on GO nanosheets, XPS measurements for GO and DT-GO were performed, as shown in Fig. 1c, d. Before the XPS test, DT-GO sample was washed with ultra-pure water and ethanol several times in order to remove the residual EDDET. The XPS spectrum of GO showed the $\mathrm{C} 1 \mathrm{~s}$ and $\mathrm{O} 1 \mathrm{~s}$ peaks, and the $\mathrm{C} 1 \mathrm{~s}$ and $\mathrm{O} 1 \mathrm{~s}$ spectra inserted in Fig. 1c indicated the carbon atoms in $\mathrm{C}-\mathrm{O}$ and $\mathrm{C}=\mathrm{O}$ bands. Whereas, the XPS spectrum of DT-GO displayed the new S1 s and S2p peaks compared to that of GO. The S2p1 and S2p3 fitting scanning spectra proved the formation of $\mathrm{C}-\mathrm{S}$ bonds between GO and EDDET molecules.

Subsequently, TEM was used to observe the morphology of GO and DT-GO nanosheets, the results were shown in Scheme $1 \mathrm{a}$ and Fig. 1S. Both GO and DT-GO nanosheets were dispersed in Millipore water and sonicated for $30 \mathrm{~min}$ before preparing the copper grids. The large flakes of GO were produced in this study, Fig. 1S showed that the prepared GO nanosheets were thick. It could be clearly observed that GO presented almost transparent singlelayer structure with folds. The thickness of GO layer were approximately $1.25 \mathrm{~nm}$ (Fig. 2S), this obtained results speculated that the prepared GO sheets were composed of approximately two stacked individual monatomic graphene oxide layers [41, 42]. However, the GO was modified by EDDET, more layers stacked together, the size of DT-GO flakes decreased, single-layer GO sheets folded.

\subsection{FT-IR analysis of GA and DT-GA nanocomposites}

GA and DT-GA nanocomposites were prepared by freezedrying method. FT-IR was utilized to investigate the possible interactions between GO or DT-GO and alginate macromolecular chain, the results were shown in Fig. 2 . The obvious peaks at 1401 and $1028 \mathrm{~cm}^{-1}$ in the FT-IR spectrum of $\mathrm{GA}$ were attributed to deformation of $\mathrm{O}-\mathrm{H}$ bands and stretching $\mathrm{C}-\mathrm{O}$ bands from $\mathrm{GO}$, respectively. The peak centered at $3430 \mathrm{~cm}^{-1}$, due to $\mathrm{O}-\mathrm{H}$ groups, which was clearly strengthened comparing to that of GO. It was shown that the weak peaks at 1095 and $1059 \mathrm{~cm}^{-1}$ were ascribed to the stretching vibration $\mathrm{C}-\mathrm{O}-\mathrm{C}$ ether groups in alginate for GA nanocomposite spectra (Fig. 2a). The distinct peak at $1612 \mathrm{~cm}^{-1}$ appeared was due to $\mathrm{C}=\mathrm{C}$ band stretching from $\mathrm{GO}$, and this peak gradually increased with enhancing the concentration of GO in GA nanocomposite. These significant characteristic peaks comparing to pure $\mathrm{GO}$ spectrum indicated that GO nanosheets indeed interacted to the alginate chain. In addition, the observed increase of the $\mathrm{O}-\mathrm{H}$ band proved that the $\mathrm{H}$-bonding existed between $\mathrm{C}=\mathrm{O}$ or $\mathrm{C}-\mathrm{O}$ and $\mathrm{OH}$. However, the evident peaks at 2929, 2856, $782 \mathrm{~cm}^{-1}$ appeared for DT-GA nanocomposite compared to GA spectra (Fig. 2b). The peak at $782 \mathrm{~cm}^{-1}$ was due to C-S band of DT-GO nanosheets. The peaks at
Fig. 2 a The FT-IR spectra of GA nanocomposites with different GO concentration; b The FT-IR spectra of DT-GA nanocomposites with different DT-GO concentration
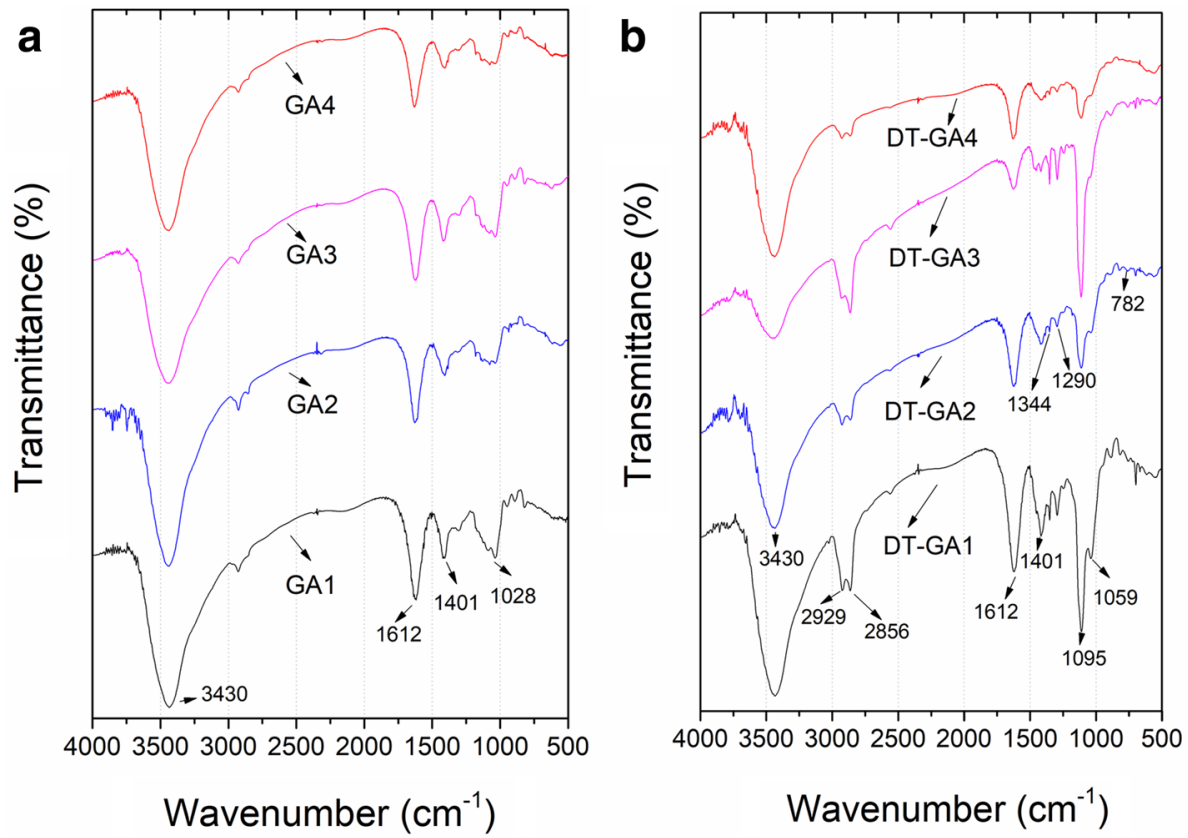

SN Applied Sciences A SPRINGER NATURE journa 
$2929 \mathrm{~cm}^{-1}$ and $2856 \mathrm{~cm}^{-1}$ exhibited gradually increased methylene groups intensities. The noticeable peaks at 1095 and $1059 \mathrm{~cm}^{-1}$ from alginate certified that the different interaction between DT-GO and alginate biopolymer. The spectrum of DT-GA showed a highest peak at $1095 \mathrm{~cm}^{-1}$, and lowest peak centered at $3430 \mathrm{~cm}^{-1}$ [43].

\subsection{Microstructure morphology analysis of GA and DT-GA nanocomposites}

The cross-sectional morphologies of GA and DT-GA nanocomposites have been investigated by SEM, the results were shown in Figs. 3 and 4. The interconnected porous microstructure morphologies were observed for GA and DT-GA nanocomposites. The morphology structure of GA nanocomposite significantly varied with the increase of GO nanosheets concentration. For GA4 and GA3 nanocomposites, the apparent porous polymer structure was shown (Fig. 3a-d), the pore size of open pores was calculated by 20 of random SEM images with using Image J software (Fig. 3S). During the calculation, all pores over $1 \mu \mathrm{m}$ were counted. The pore size of GA4 nanocomposite was about $23.8 \pm 4.8 \mu \mathrm{m}$, and $46 \%$ of pores was in the range of 1-10 $\mu \mathrm{m}$. For GA3 nanocomposite, the pore size
Fig. 3 Comparison and cross-sectional morphology and structure of graphene oxide/alginate (GA) nanocomposites. SEM images of GA4 nanocomposite $(\mathbf{a}, \mathbf{b}), \mathrm{GA} 3$ nanocomposite $(\mathbf{c}, \mathbf{d}), \mathrm{GA} 2$ nanocomposite $(\mathbf{e}, \mathbf{f})$, and GA1 nanocomposite $(\mathbf{g}, \mathbf{h})$. From left to right: low-resolution SEM images $(\mathbf{a}, \mathbf{c}, \mathbf{e}, \mathbf{g})$ and lowresolution SEM images $(\mathbf{b}, \mathbf{d}, \mathbf{f}$, h), the images inserted in left row were enlarged to right row at a higher magnifications

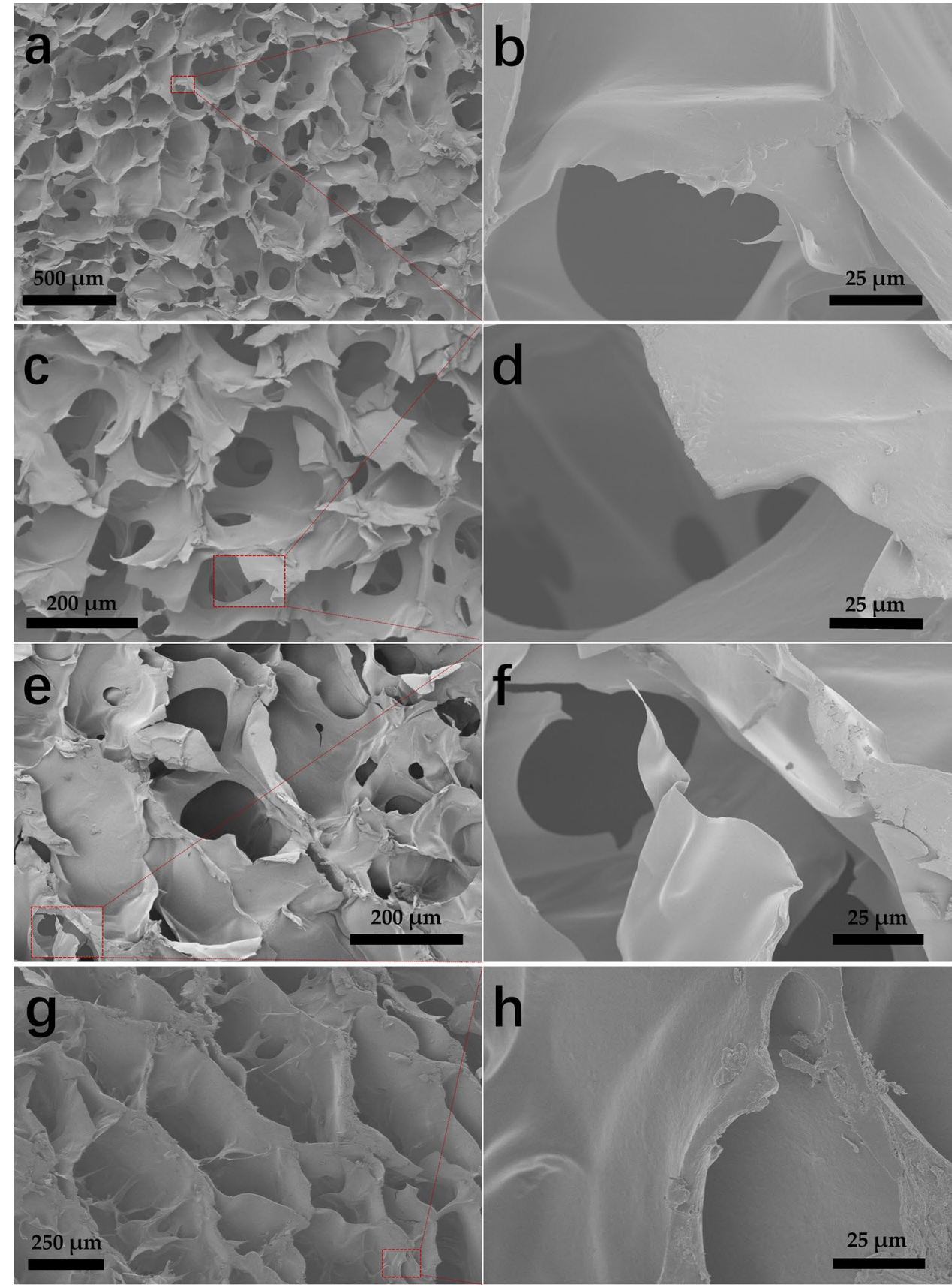


Fig. 4 Comparison and crosssectional morphology and structure of dithiol-modified graphene oxide/alginate (DT-GA) nanocomposites. SEM images of DT-GA4 nanocomposite $(\mathbf{a}, \mathbf{b})$, DT-GA3 nanocomposite (c, d), DT-GA2 nanocomposite $(\mathbf{e}, \mathbf{f})$, and DT-GA1 nanocomposite $(\mathbf{g}, \mathbf{h})$. From left to right: low-resolution SEM images $(\mathbf{a}, \mathbf{c}, \mathbf{e}, \mathbf{g})$ and lowresolution SEM images $(\mathbf{b}, \mathbf{d}, \mathbf{f}$, h), the images inserted in left row were enlarged to right row at a higher magnifications
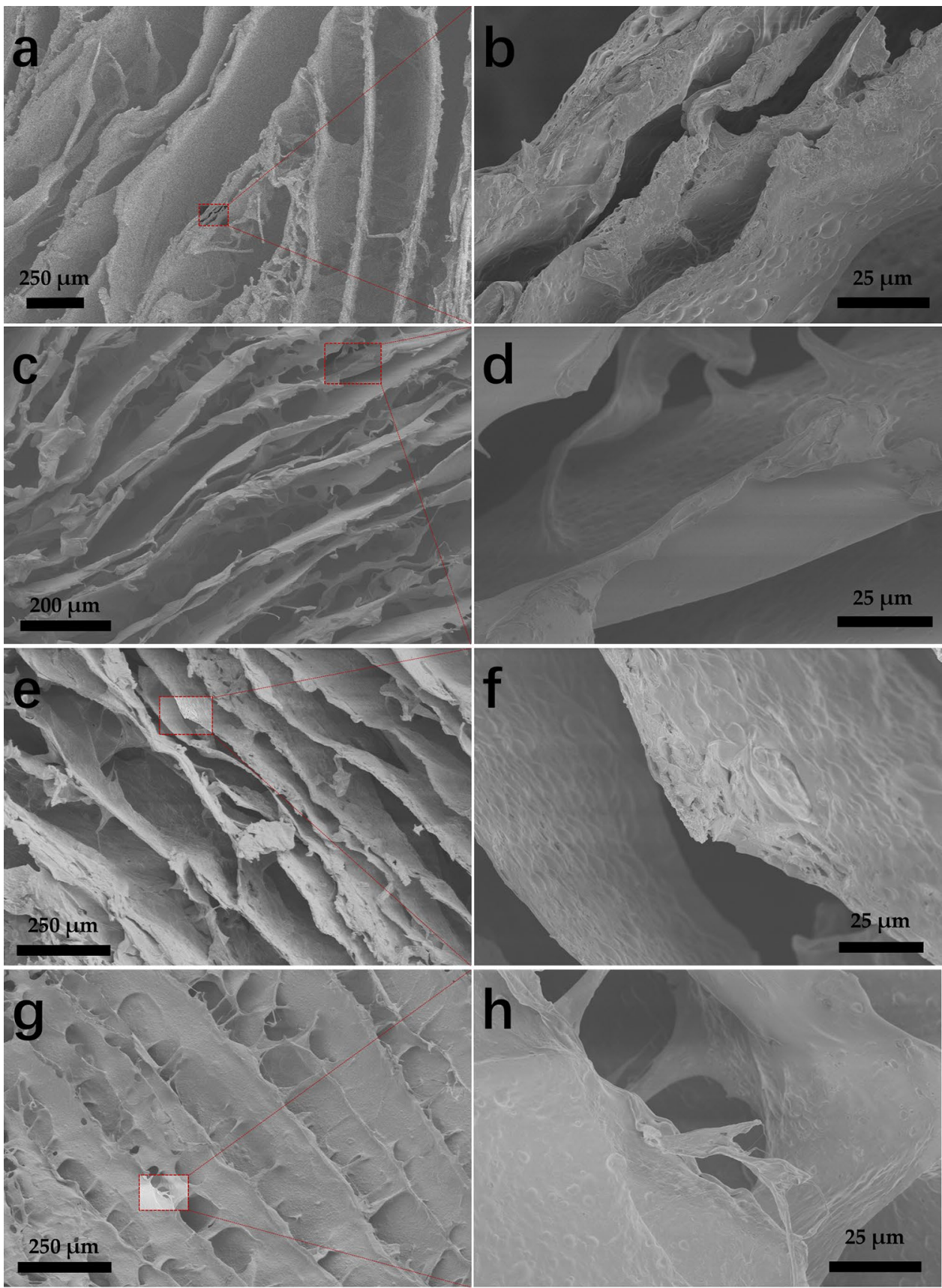

decreased to $13.6 \pm 3.9 \mu \mathrm{m}$, and $69 \%$ of pores was in the range of 1-10 $\mu \mathrm{m}$. Thus, the porous structure of GA nanocomposites (GA4, GA3) was composed of micropores and macropores, and the number of micropores (mainly 1-10 $\mu \mathrm{m}$ ) increased with enhancing GO concentration from 11.1 to 12.5 wt.\% in GA nanocomposite. While the concentration of GO increased to $14.3 \mathrm{wt} . \%$ (GA2) and $16.7 \mathrm{wt} . \%$ (GA1), the morphology of GA nanocomposites obviously changed, the laminar pore structure was observed, and the pore wall became rough (Fig. 3e-h). Because that the shape of most pores was irregular, so the size of GA1 and GA2 nanocomposites was not calculated. It was apparently that the thickness of pore wall increased with increasing the GO concentration for GA nanocomposite. For GA1 nanocomposite with the highest GO concentration, the alginate fibers were observed between laminar walls, in addition, the thickness of pore walls reached to 4-18 $\mu \mathrm{m}$.

Due to the physicochemical properties of DT-GO, the laminar network structure was observed for DT-GA nanocomposites with different DT-GO concentrations (Fig. 4). For DT-GA4 nanocomposite of the lowest DT-GO concentration at $11.1 \mathrm{wt} \%$, the random aligned laminar fabrics were observed, and the presented corrugation on the pore wall suggested the existence of DT-GO nanosheets, 
as shown in Fig. 4a, b. However, with increasing the concentration of DT-GO, the uniformly aligned structure was gradually formed, and the pore wall became obviously rougher. In addition, the distance between composite layers decreased with increasing DT-GO concentration. While the concentration of DT-GO concentration increased to $16.7 \mathrm{wt} . \%$, the composite layers almost connected together, and the surface of pore wall was apparently covered with massive GT-GO nanosheets (Fig. 4g,h) [44].

Furthermore, EDX was conducted to study the distribution of each element in GA and DT-GA nanocomposites, the results were shown in Fig. 4. The EDX spectra recorded from GA and DT-GA nanocomposites presented on both of pore walls were similar, except for the content of $S$ element. The content of various elements, including $\mathrm{C}, \mathrm{O}, \mathrm{Na}, \mathrm{S}$, from $\mathrm{GA} 3$ and DT-GA3 nanocomposites were analyzed (Tables $1 \mathrm{~S}$ and $2 \mathrm{~S}$ ). A little of S element (0.74 wt.\%) was detected in GA3 nanocomposite, was due to the residual sulfuric acid left during the preparation of $\mathrm{GO}$ by Hummers methods. The content of $\mathrm{S}$ increased to $2.76 \mathrm{wt} . \%$ in DT-GA3 nanocomposite was on account of dispersed dithiol modified GO. The presence of small amounts of $\mathrm{Al}$ and Pt in both GA and DT-GA scaffolds, mainly because that the aluminum SEM fixing table was used, and the scaffolds were coated with platinum (Pt).

\subsection{Porosity analysis of GA and DT-GA nanocomposites}

Regarding the different interaction forces between $\mathrm{GO}$ and DT-GO on alginate biopolymer chain, as well as significant morphology differences, the porosity of GA and DT-GA nanocomposites, as an important parameter, was measured. For GA scaffolds (Fig. 5a), as the GO concentration increased from 11.1 to $16.7 \mathrm{wt} . \%$, the porosity gradually decreased from 76.4 to $66.2 \mathrm{wt} . \%$. However, for DT-GA nanocomposite (Fig. 5b), the porosity firstly increased then decreased with increasing DT-GO concentration, and DT-GA nanocomposite showed the highest porosity values at the DT-GO concentration of 14.3 wt.\%.
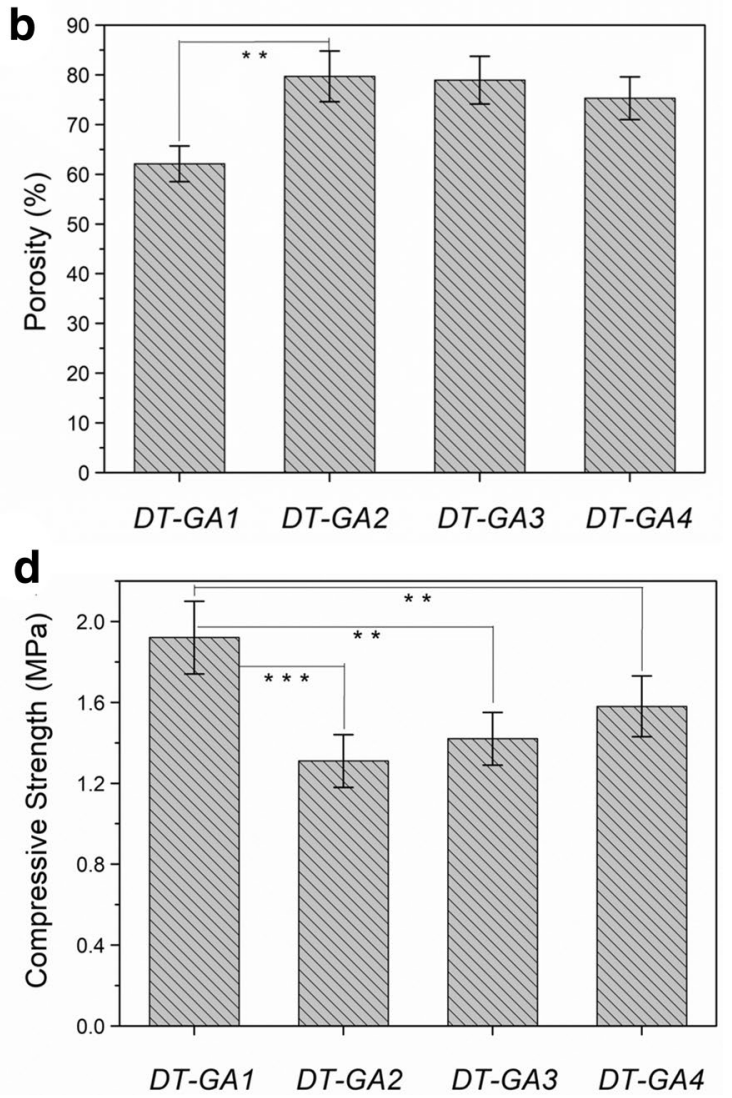

tively; $\mathbf{c}$, $\mathbf{d}$ were the compressive strengths of GA and DT-GA nanocomposites with different DT-GO concentrations respectively, ${ }^{* *} p<0.01,{ }^{* * *} p<0.001$
Fig. 5 The porosity and compressive strengths of the prepared GA and DT-GA nanocomposites. $\mathbf{a}$, b were the porosity of GA and DT-GA nanocomposite with different GO concentration respec-
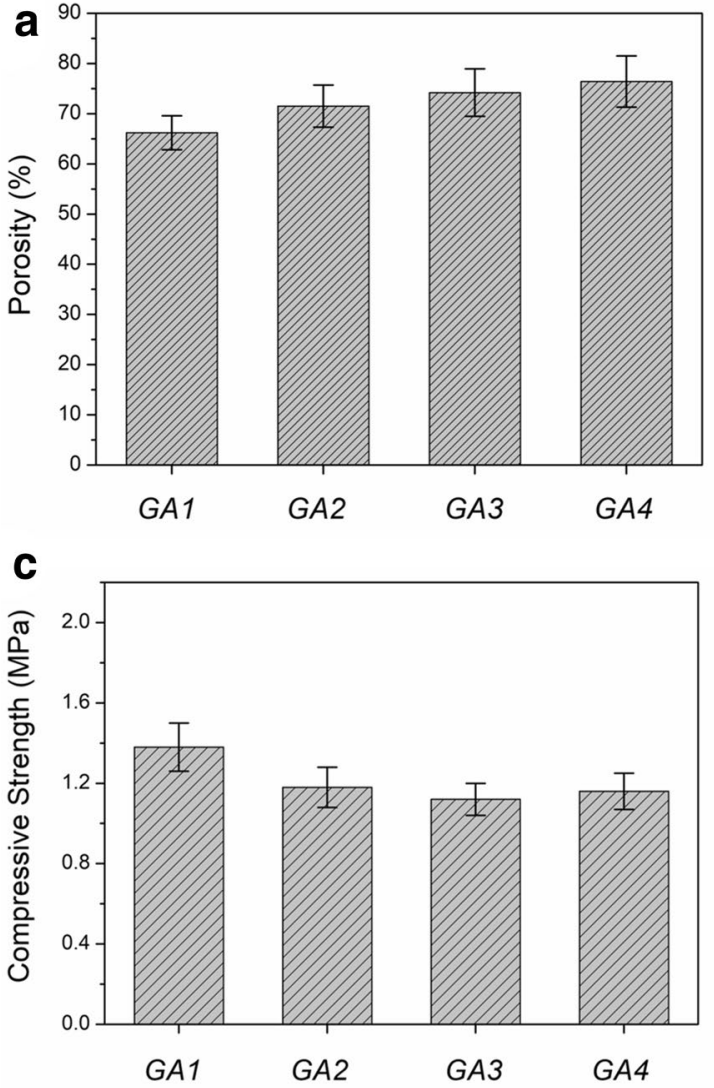

SN Applied Sciences

A SPRINGER NATURE journal 


\subsection{Compressive strengths of GA and DT-GA nanocomposites}

The compressive strength of nanocomposite was an important criterion for bone tissue engineering application, and the compressive strength of the spongy bone was in range of $0.2-4 \mathrm{MPa}$ according to previous reports [45-47]. Figure 5c, d showed that the compressive strengths of prepared GA and DT-GA nanocomposites were in the range of 1-2 MPa. As the concentration of GO or DT-GO at $16.7 \mathrm{wt} \%$, the compressive strengths of GA or DT-GA nanocomposites (GA1 and DT-GA1) showed highest values, and DT-GA nanocomposites showed a higher compressive strength value than that of GA nanocomposites. For DT-GA nanocomposites, the compressive strength firstly decreased then increased with decreasing the concentration of DT-GO nanosheets. In addition, the DT-GA nanocomposites showed the highest compressive strength values at the DT-GO concentration of $14.3 \mathrm{wt} \%$.

\subsection{In vitro study of GA and DT-GA nanocomposites}

\subsubsection{CCK-8 analysis}

The BMSCs were seeded on both GA and DT-GA nanocomposites and cultured for 1,3 and 5 days. The BMSCs viability in nanocomposites were evaluated by treating with CCK-8 solution, then O.D value at $570 \mathrm{~nm}$ was tested by ELISA to indicate the presence of metabolically active cells, at the same time, bare cultured BMSCs was used as a control group, and the results were presented in Fig. 6a. Firstly, the cytocompatibility of dithiol modified GO nanosheets was investigated by culturing with BMSCs, and the result showed that the DT-GO had a good cytocompatibility as well as GO (Fig. 5S). According to CCK-8 results, the proliferation of BMSCs on both GA and DT-GA nanocomposites increased over days. For GA nanocomposites, the O.D values increased with the decrease of $\mathrm{GO}$ concentration. Furthermore, the O.D value of GA1 nanocomposite with the highest $\mathrm{GO}$ concentration increased slower from day 3-5 compared to other GA nanocomposites, and GA4 nanocomposite with the lowest $\mathrm{GO}$ concentration showed a highest O.D value at day 5. However, DT-GA nanocomposites behaved the increasing O.D values with increasing DT-GO concentration at day 1 and 3, and DT-GA3 nanocomposite with $12.5 \mathrm{wt} \%$ DT-GO concentration showed the highest O.D value at day 5 .

\subsubsection{ALP activities analysis}

ALP activity was performed on BMSCs in contact with both GA and DT-GA nanocomposites on day 2, 6 and 10 after incubation, and the results were shown in Fig. 6b. At day
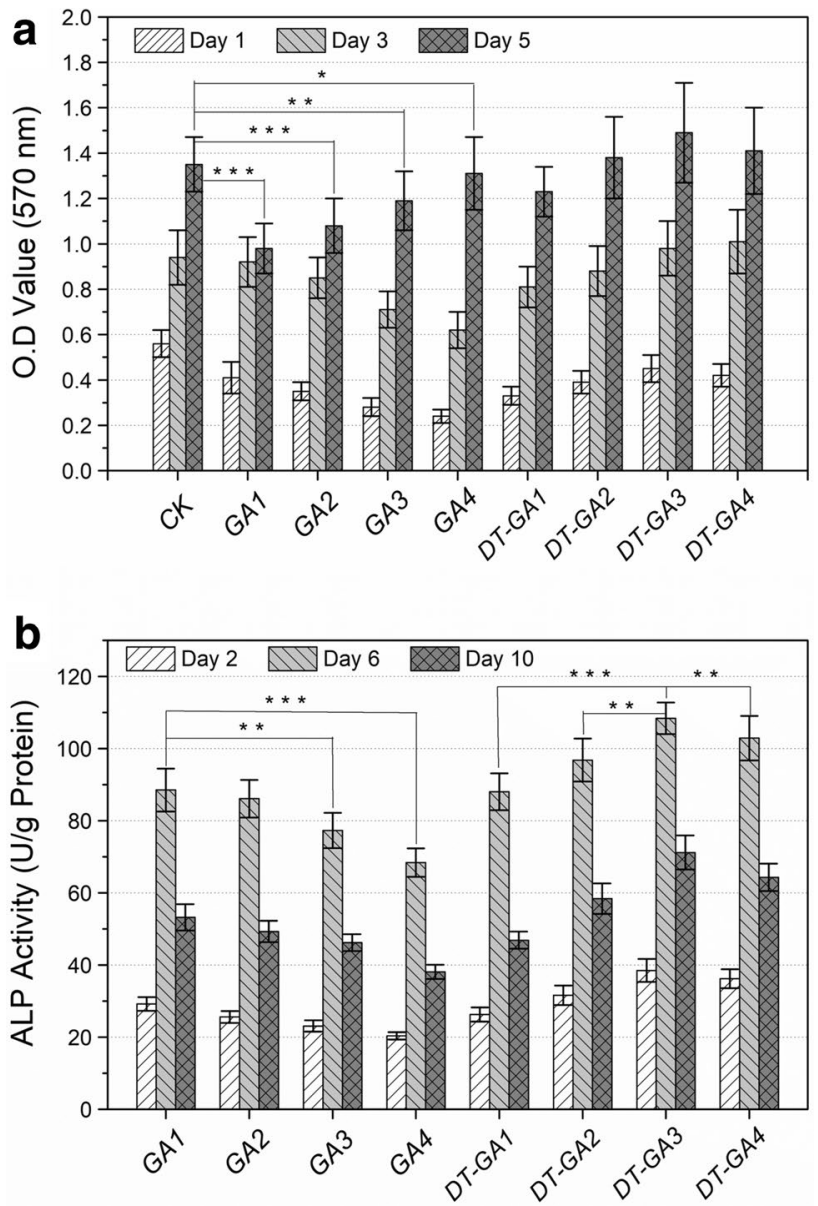

Fig. 6 a In vitro cytocompatibility of the prepared GA and DT-GA nanocomposites after cultured with BMSCs for different days. $\mathrm{OD}_{570 \mathrm{~nm}}$ values in CCK-8 assays BMSCs seeded on the GA and DT-GA nanocomposites after 1, 3, and 5 days compared with the control group. $\mathbf{b}$ Changes in ALP activity in BMSCs seeded on both GA and DT-GA nanocomposites after incubation for 10 days period, ${ }^{*} p<0.05,{ }^{* *} p<0.01,{ }^{* * *} p<0.001$

1, low ALP activity for all nanocomposites was detected, indicating little BMSCs differentiated into osteoblast phenotype. All samples showed a highest ALP activity at day 6. However, the ALP activity decreased at day 10 in all samples. For GA nanocomposite, the ALP activity decreased with the decrease of $\mathrm{GO}$ concentration. DT-GA nanocomposites expressed a higher ALP activity than that of GA nanocomposites with the same concentration of alginate at same day, and DT-GA3 nanocomposite with $12.5 \mathrm{wt} \%$ DT-GO concentration showed the highest ALP activity at day 2,6 and 10 .

\subsubsection{Fluorescent microscopy analysis of BMSCs seeded on nanocomposites}

Furthermore, the BMSCs seeded on both GA and DT-GA nanocomposites were assessed by fluorescent microscopy 

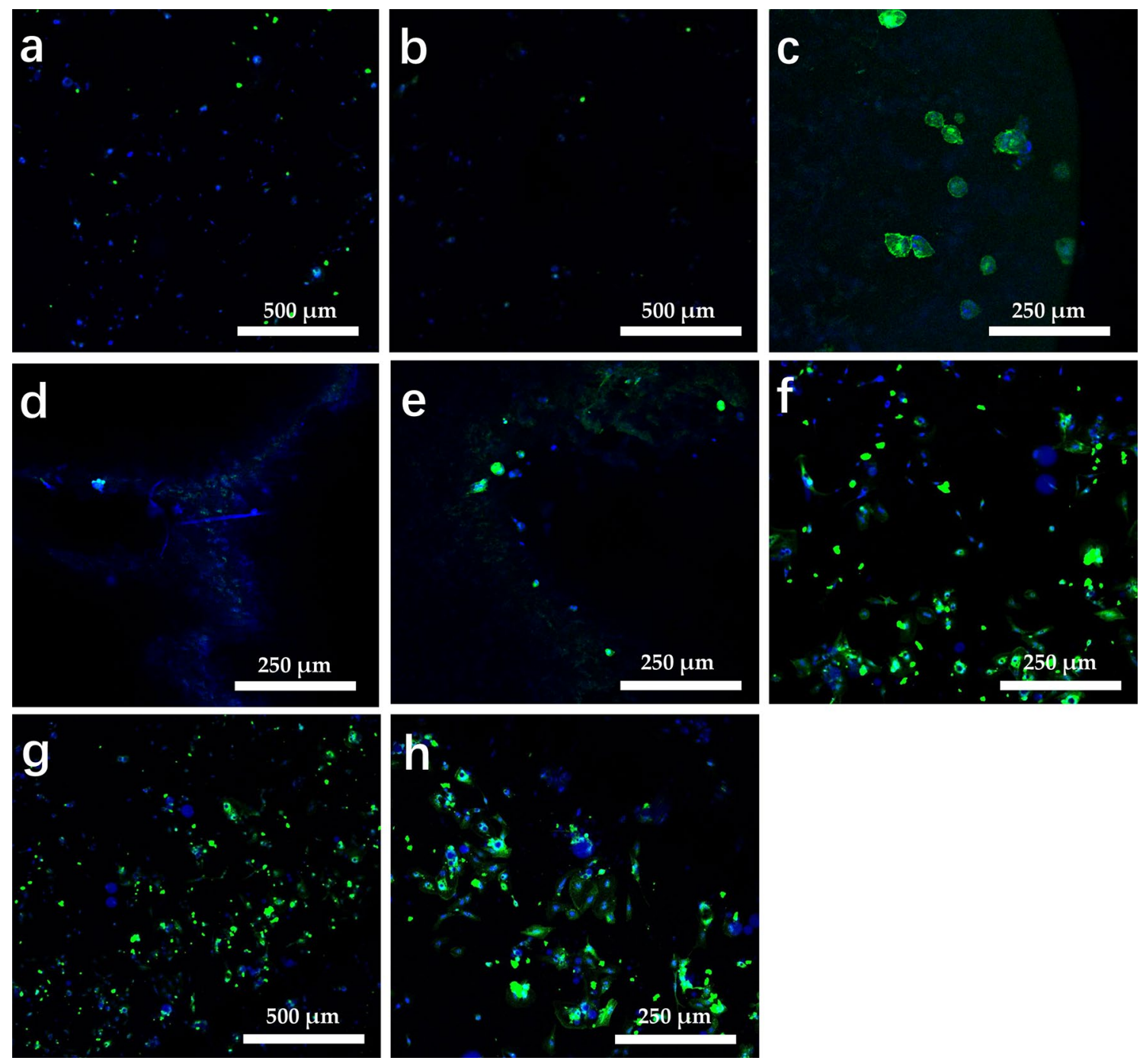

Fig. 7 Representative fluorescent microscopy images of BMSCs cultured with GA and DT-GA nanocomposites for 5 days. a GA1 nanocomposite; b GA2 nanocomposite; c GA3 nanocomposite; d GA4 nanocomposite; e DT-GA1 nanocomposite; $\mathbf{f}$ DT-GA2 nanocompos- ite; g DT-GA3 nanocomposite; $\mathbf{h}$ DT-GA4 nanocomposite. Green: cytoskeleton stained by phalloidin-FITC, Blue: nucleus stained by DAPI images, and the results were presented in Fig. 7. The BMSCs number density on both nanocomposites increased with increasing alginate concentration. In contrast of the GA nanocomposites at the same concentration of alginate, the number of BMSCs seeded on DT-GA nanocomposites was higher. For GA4 nanocomposite, it was obviously that the cells adhered on pore wall between laminar layers. The highest number of BMSCs was observed on DT-GA3 nanocomposite, which was consistent with CCK-8 assay result.

\section{Discussion}

The porous composite with interconnected structure could provide as extracellular matrix (ECM) for cell adhesion and proliferation, which were significantly influenced by the morphology and composition of composites. In this paper, based on the functional groups on GO nanosheets, GO nanosheets were modified by 
using dithiol chemicals EDDET, the obtained DT-GO nanosheets showed the different physicochemical characteristics confirmed by FT-IR, XRD and XPS analyses. The carboxyl groups on the edge of GO nanosheets could interact with sulfydryl groups of EDDET, which was confirmed by that the new C-S bond was detected by FT-IR and XPS in DT-GO samples (Fig. 1). The sulfydryl groups of EDDET could be used to prepare organic/ inorganic composite with improved mechanical strength via covalent bond $[48,49]$. The EDDET molecules were facilely bonded on the surface of $\mathrm{GO}$, the morphology of modified $\mathrm{GO}$ was influenced by the reaction temperature. According to our previous report, the reaction temperature was set at $90^{\circ} \mathrm{C}$, the layer distance was about $0.42 \mathrm{~nm}$ [27]. However, in this study, the reaction temperature was decreased to $60^{\circ} \mathrm{C}$, the value deceased to $0.08 \mathrm{~nm}$. The $d$-spacing between $\mathrm{GO}$ nanosheets could be calculated by Bragg's law [50]. In addition, the degree of crystallinity was also increased with decreasing the reaction temperature which was tested by XRD. The morphology of DT-GO nanosheets obviously changed compared to that of GO, more layers stacked together because of EDDET ligation function, and the flake size was shrunken. Those features obviously impacted the structure of DT-GA nanocomposite comparing to GA nanocomposite.

It was well known that the interconnected structure of nanocomposite as scaffold played a critical role in bone tissue engineering. The porous nanocomposite could provide a template for cell attachment and proliferation, and the porous structure was beneficial for the mass and nutrient transport, as well as supporting newly formed tissue $[45,46,51]$. Figures 3 and 4 showed typical interconnected porous structures for prepared GA and DT-GA nanocomposites. The small amount of GO incorporated into alginate chain didn't alter the porous structure and morphology of GA nanocomposite [52]. However, the pore arrangement and pore size of nanocomposite were improved by the addition of GO, and the specific surface areas was also increased [53]. In our study, with increasing the concentration of GO in GA nanocomposites, the laminar structure was gradually formed, which mainly due to the increase of acting forces between GO layers. The aligned structure of GA nanocomposites exhibited excellent mechanical strength and elasticity $[54,55]$. As GO was modified by dithiol molecule, and incorporated into alginate network structure, the uniformly aligned structure was readily formed for DT-GA nanocomposites in comparison with GA nanocomposites at the same concentration of alginate. The stronger interaction between DT-GO and alginate chain was shown in DT-GA nanocomposites than that in GA nanocomposites (Fig. 2). Moreover, the round shape of pores in cross-sectional nanocomposites was gradually changed to be of irregular shape. The composite fibers connected between laminar in DT-GA nanocomposites were observed. The above characteristics could further influence the porosity and compressive strength of nanocomposites.

Although, GO nanosheets could reinforced polymerbased composite, the compressive strength of composites still depended on the polymer performance and the morphology of composite [56]. The porosity and compressive strength of both GA and DT-GA nanocomposites were investigated in this paper, as shown in Fig. 5 . The porosity of GA nanocomposites showed the lowest value at the highest concentration of $\mathrm{GO}(66.2 \%)$, and the porosity of DT-GA nanocomposites continued to decease at the GO concentration of $62.1 \%$, mainly because that the laminar structure formed in DT-GA nanocomposites. While the concentration of DT-GO decreased to $14.3 \%$ (DT-GA2), the DT-GA nanocomposites showed the highest porosity. Few studies reported the relationship between porosity and porous structure (typical pore structure or laminar pore structure) [57]. Here, we could conclude that the porosity of as-prepared nanocomposites was obviously influenced by the porous structure, the nanocomposite with a laminar structure showed a higher porosity than the nanocomposites with a typical porous structure. However, as increasing the concentration of DT-GO, the formed laminar easily connected and stacked, then the porosity would be apparently decreased. As we confirmed that the compressive strength was mainly related to the porosity. Generally, there was a tradeoff between mechanical strength and porosity for porous nanocomposite [5, 58]. It was shown that the inverse relationship between compressive strength and porosity for the prepared nanocomposites. The compressive strength of DT-GA nanocomposites was significantly improved in comparison with GA nanocomposites, which was mainly due to the great different physicochemical properties of DT-GO sheets comparing to that of GO, and the obtained compressive strength value was also higher than that of reported composites [59,60]. Many DT-GO nanosheets were observed on the surface of pore wall, which was confirmed by EDX analysis (Fig. 4S), and the interaction between DT-GO and alginate chains played an important role for improving the compressive strength of nanocomposite. In addition, the inhomogeneous distribution and agglomeration of the GO or DT-GO were not observed in the alginate matrix, which might result in poor mechanical strength of nanocomposites [61]. The compressive strength of obtained nanocomposites was in range of spongy bone strength (0.2-4 MPa), which was suitable for the blame bearing bone applications.

Next, all nanocomposites were implanted into the body must be possessing of good biocompatibility. 
Indispensably, the cytocompatibility of prepared nanocomposites was critical factor for the success of cell/scaffolds construction in bone tissue engineering. The BMSCs has been widely used for cell-engineered scaffolds before implantation into body [62]. The CCK-8 assay results revealed that both GA and DT-GA nanocomposites had a good cytocompatibility after culturing with BMSCs, and the O.D value at $570 \mathrm{~nm}$ confirmed that the BMSCs had a better proliferation seeded on DT-GA nanocomposites than that on GA nanocomposites. The laminar pore structure of nanocomposites provided more cell proliferation space than typical pore structure, the same results could also be testified by fluorescent microscopy images (Fig. 7). Furthermore, the differentiation of BMSCs was an important factor for bone regeneration [62]. ALP activity was widely used for evaluating the differentiation of BMSCs into osteoblastic phenotype quantitatively [63]. ALP activity results indicated that both GA and DT-GA nanocomposites supported osteoblastic differentiation of BMSCs.

\section{Conclusions}

In summary, the dithiol molecule, EDDET, was effective as cross-linker on $\mathrm{GO}$ for altering the physicochemical properties of GO nanosheets. As DT-GO nanosheets was used as reinforcing filler to composite with alginate macromolecular chain to produce DT-GA nanocomposites. The prepared DT-GA nanocomposites showed a laminar network morphology with interconnected porous structure, and porosity and compressive strength were related to formed structure of DT-GA. In addition, such prepared DT-GA nanocomposites demonstrated excellent cytocompatibility after cultured with BMSCs, and BMSCs seeded on nanocomposites could differentiated into osteoblastic phenotype in first 10 days. This study suggest that these promising mechanical and biological characteristics of novel dithiol-modified GO/alginate nanocomposites makes possible candidates for bone regeneration.

Acknowledgements This research was funded by the National Natural Science Foundation of China (31700840); the Key Scientific Research Project of Henan Province (18B430013); the Scientific Research Foundation of Graduate School of Xinyang Normal University (2018KYJJ48); and Wuhan Municipal Health and Family Planning Research Fund (WX18C23). This research was supported by the Nanhu Scholars Program for Young Scholars of XYNU. The authors would like to acknowledge Analysis \& Testing Center of XYNU for the use of their equipment. Finally, this work also thanks for Professor Dong Chen from Department of Orthopedics at Wuhan Hanyang Hospital for in vitro experiment and analysis.

\section{Compliance with ethical standards}

Conflict of interest The authors declare no conflict of interest.

\section{References}

1. Ram-Liebig G, Bednarz J, Stuerzebecher B, Fahlenkamp D, Barbagli G, Romano G, Balsmeyer U, Spiegeler ME, Liebig S, Knispel H (2015) Regulatory challenges for autologous tissue engineered products on their way from bench to bedside in Europe. Adv Drug Deliev Rev 82:181-191. https://doi.org/10.1016/j. addr.2014.11.009

2. Makris EA, Gomoll AH, Malizos KN, Hu JC, Athanasiou KA (2015) Repair and tissue engineering techniques for articular cartilage. Nat Rev Rheumatol 11:21-34. https://doi.org/10.1038/nrrhe um.2014.157

3. Black CR, Goriainov V, Gibbs D, Kanczler J, Tare RS, Oreffo RO (2015) Bone tissue engineering. Curr Mol Biol Rep 1:132-140. https://doi.org/10.1007/s40610-015-0022-2

4. Wu S, Liu X, Yeung KWK, Liu C, Yang X (2014) Biomimetic porous scaffolds for bone tissue engineering. Mater Sci Eng Rep 80:136. https://doi.org/10.1016/j.mser.2014.04.001

5. Hollister SJ (2005) Porous scaffold design for tissue engineering. Nat Mater 4:518-524. https://doi.org/10.1038/nmat1683

6. Woodard JR, Hilldore AJ, Lan SK, Park CJ, Morgan AW, Eurell JAC, Clark SG, Wheeler MB, Jamison RD, Wagoner Johnson AJ (2007) The mechanical properties and osteoconductivity of hydroxyapatite bone scaffolds with multi-scale porosity. Biomaterials 28:45-54. https://doi.org/10.1016/j.biomateria Is.2006.08.021

7. Sabree I, Gough JE, Derby B (2015) Mechanical properties of porous ceramic scaffolds: influence of internal dimensions. Ceram Int 41:8425-8432. https://doi.org/10.1016/j.ceram int.2015.03.044

8. Roohani-Esfahani SI, Newman P, Zreiqat H (2016) Design and fabrication of 3D printed scaffolds with a mechanical strength comparable to cortical bone to repair large bone defects. Sci Rep 6:19468. https://doi.org/10.1038/srep19468

9. Pina S, Oliveira JM, Reis RL (2015) Natural-based nanocomposites for bone tissue engineering and regenerative medicine: a review. Adv Mater 27:1143-1169. https://doi.org/10.1002/ adma.201403354

10. Bose S, Vahabzadeh S, Bandyopadhyay A (2013) Bone tissue engineering using 3D printing. Mater Today 16:496-504. https ://doi.org/10.1016/j.mattod.2013.11.017

11. Kim J, Kim YR, Kim Y, Lim KT, Seonwoo H, Park S, Cho SP, Hong $\mathrm{BH}$, Choung PH, Choung YH, Chung JH (2013) Graphene-incorporated chitosan substrata for adhesion and differentiation of human mesenchymal stem cells. J Mater Chem B 1:933-938. https://doi.org/10.1039/c2tb00274d

12. Lu J, He YS, Cheng C, Wang Y, Qiu L, Li D, Zou D (2013) Self-supporting graphene hydrogel film as an experimental platform to evaluate the potential of graphene for bone regeneration. Adv Funct Mater 23:3494-3502. https://doi.org/10.1002/adfm.20120 3637

13. Nayak TR, Andersen $H$, Makam VS, Khaw C, Bae S, Xu X, Ee PLR, Ahn JH, Hong BH, Pastorin G, Özyilmaz B (2011) Graphene for controlled and accelerated osteogenic differentiation of human mesenchymal stem cells. ACS Nano 5:4670-4678. https://doi. org/10.1021/nn200500h

14. Jinschek JR, Yucelen E, Calderon HA, Freitag B (2011) Quantitative atomic 3-D imaging of single/double sheet graphene structure. Carbon 49:556-562. https://doi.org/10.1016/j.carbo n.2010.09.058

15. Goenka S, Sant V, Sant S (2014) Graphene-based nanomaterials for drug delivery and tissue engineering. J Control Release 173:75-88. https://doi.org/10.1016/j.jconrel.2013.10.017

16. Gu M, Liu Y, Chen T, Du F, Zhao X, Xiong C, Zhou Y (2014) Is graphene a promising nano-material for promoting surface 
modification of implants or scaffold materials in bone tissue engineering? Tissue Eng B Rev 20:477-491. https://doi. org/10.1089/ten.teb.2013.0638

17. Menaa F, Abdelghani A, Menaa B (2015) Graphene nanomaterials as biocompatible and conductive scaffolds for stem cells: impact for tissue engineering and regenerative medicine. J Tissue Eng Regen Med 9:1321-1338. https://doi.org/10.1002/ term. 1910

18. Niu Z, Chen J, Hng HH, Ma J, Chen X (2012) A leavening strategy to prepare reduced graphene oxide foams. Adv Mater 24:41444150. https://doi.org/10.1002/adma.201200197

19. Zhao Y, Wang Y, Niu C, Zhang L, Li G, Yang Y (2018) Construction of polyacrylamide/graphene oxide/gelatin/sodium alginate (PAM/GO/Gel/SA) composite hydrogel for promoting Schwann cells growth. J Biomed Mater Res A 106:1951-1964. https://doi. org/10.1002/jbm.a.36393

20. Georgakilas V, Tiwari JN, Kemp KC, Perman JA, Bourlinos AB, Kim KS, Zboril R (2016) Noncovalent functionalization of graphene and graphene oxide for energy materials, biosensing, catalytic, and biomedical applications. Chem Rev 116(9):5464-5519. https ://doi.org/10.1021/acs.chemrev.5b00620

21. Tang S, Wu W, Liu L, Cao Z, Wei X, Chen Z (2017) Diels-Alder reactions of graphene oxides: greatly enhanced chemical reactivity by oxygen-containing groups. Phys Chem Chem Phys 19:11142-11151. https://doi.org/10.1039/c7cp01086a

22. Tan C, Wu X, Wang Q, Tang P, Shi X, Zhan S, Xi Z, Fu X (2017) Graphene oxide: a perfect material for spatial light modulation based on plasma channels. Materials 10:354. https://doi. org/10.3390/ma10040354

23. Depan D, Girase B, Shah JS, Misra RDK (2011) Structure-processproperty relationship of the polar graphene oxide-mediated cellular response and stimulated growth of osteoblasts on hybrid chitosan network structure nanocomposite scaffolds. Acta Biomater 7:3432-3445. https://doi.org/10.1016/j.actbi o.2011.05.019

24. Wan C, Chen B (2011) Poly( $\varepsilon$-caprolactone)/graphene oxide biocomposites: mechanical properties and bioactivity. Biomed Mater 6:055010. https://doi.org/10.1088/1748-6041/6/5/05501 0

25. Song J, Gao H, Zhu G, Cao X, Shi X, Wang Y (2015) The preparation and characterization of polycaprolactone/graphene oxide biocomposite nanofiber scaffolds and their application for directing cell behaviors. Carbon 95:1039-1050. https://doi. org/10.1016/j.carbon.2015.09.011

26. Wu D, Backstrom E, Hakkarainen M (2017) Starch derived nanosized graphene oxide functionalized bioactive porous starch scaffolds. Macromol Biosci 17:1600397. https://doi.org/10.1002/ mabi.201600397

27. Du G, Nie L, Gao G, Sun Y, Hou R, Zhang H, Chen T, Fu J (2015) Tough and biocompatible hydrogels based on in situ interpenetrating networks of dithiol-connected graphene oxide and poly(vinyl alcohol). ACS Appl Mater Interfaces 7:3003-3008. https://doi.org/10.1021/acsami.5b00184

28. Wang J, Liu C, Shuai Y, Cui X, Nie L (2014) Controlled release of anticancer drug using graphene oxide as a drug-binding effector in konjac glucomannan/sodium alginate hydrogels. Colloid Surf B 113:223-229. https://doi.org/10.1016/j.colsu rfb.2013.09.009

29. Kang X, Wang J, Wu H, Aksay IA, Liu J, Lin Y (2009) Glucose oxidase-graphene-chitosan modified electrode for direct electrochemistry and glucose sensing. Biosens Bioelectron 25:901-905. https://doi.org/10.1016/j.bios.2009.09.004

30. Qi Y, Yang M, Xu W, He S, Men Y (2017) Natural polysaccharidesmodified graphene oxide for adsorption of organic dyes from aqueous solutions. J Colloid Interf Sci 486:84-96. https://doi. org/10.1016/j.jcis.2016.09.058
31. Yadav M, Rhee KY, Park SJ (2014) Synthesis and characterization of graphene oxide/carboxymethylcellulose/alginate composite blend films. Carbohydr Polym 110:18-25. https:// doi.org/10.1016/j.carbpol.2014.03.037

32. Wicklein B, Kocjan A, Salazar-Alvarez G, Carosio F, Camino G, Antonietti M, Bergstrom $L$ (2014) Thermally insulating and fire-retardant lightweight anisotropic foams based on nanocellulose and graphene oxide. Nat Nanotechnol 10:277-283. https://doi.org/10.1038/nnano.2014.248

33. Yang X, Tu Y, Li L, Shang S, Tao X (2010) Well-dispersed chitosan/graphene oxide nanocomposites. ACS Appl Mater Interfaces 2:1707-1713. https://doi.org/10.1021/am100222m

34. Lee KY, Mooney DJ (2012) Alginate: properties and biomedical applications. Prog Polym Sci 37:106-126. https://doi. org/10.1016/j.progpolymsci.2011.06.003

35. Liu S, Li Y, Li L (2017) Enhanced stability and mechanical strength of sodium alginate composite films. Carbohydr Polym 160:62-70. https://doi.org/10.1016/j.carbpol.2016.12.048

36. Chang C, Duan B, Zhang L (2009) Fabrication and characterization of novel macroporous cellulose-alginate hydrogels. Polymer 50:5467-5473. https://doi.org/10.1016/j.polym er.2009.06.001

37. Compton OC, Dikin DA, Putz KW, Brinson LC, Nguyen ST (2010) Electrically conductive "alkylated" graphene paper via chemical reduction of amine-functionalized graphene oxide paper. Adv Mater 22:892-896. https://doi.org/10.1002/adma.20090 2069

38. Cha C, Shin SR, Gao X, Annabi N, Dokmeci MR, Tang XS, Khademhosseini A (2013) Controlling mechanical properties of cellladen hydrogels by covalent incorporation of graphene oxide. Small 10:514-523. https://doi.org/10.1002/smll.201302182

39. Kwisnek L, Goetz J, Meyers KP, Heinz SR, Wiggins JS, Nazarenko $\mathrm{S}$ (2014) PEG containing Thiol-Ene network membranes for $\mathrm{CO}_{2}$ separation: effect of cross-linking on thermal, mechanical, and gas transport properties. Macromolecules 47:3243-3253. https ://doi.org/10.1021/ma5005327

40. Nie H, Fu L, Zhu J, Yang W, Li D, Zhou L (2018) Excellent tribological properties of lower reduced graphene oxide content copper composite by using a one-step reduction molecular-level mixing process. Materials 11:600. https://doi.org/10.3390/ma110 40600

41. Lian P, Zhu X, Liang S, Li Z, Yang W, Wang H (2010) Large reversible capacity of high quality graphene sheets as an anode material for lithium-ion batteries. Electrochim Acta 55:3909-3914. https://doi.org/10.1016/j.electacta.2010.02.025

42. Wu ZS, Ren W, Gao L, Liu B, Jiang C, Cheng HM (2009) Synthesis of high-quality graphene with a pre-determined number of layers. Carbon 47:493-499. https://doi.org/10.1016/j.carbo n.2008.10.031

43. Fan J, Shi Z, Lian M, Li H, Yin J (2013) Mechanically strong graphene oxide/sodium alginate/polyacrylamide nanocomposite hydrogel with improved dye adsorption capacity. J Mater Chem A 1:7433. https://doi.org/10.1039/c3ta10639j

44. Zhang $\mathrm{K}$, Zheng $\mathrm{H}$, Liang S, Gao C (2016) Aligned PLLA nanofibrous scaffolds coated with graphene oxide for promoting neural cell growth. Acta Biomater 37:131-142. https://doi. org/10.1016/j.actbio.2016.04.008

45. Nie L, Chen D, Fu J, Yang S, Hou R, Suo J (2015) Macroporous biphasic calcium phosphate scaffolds reinforced by poly-L-lactic acid/hydroxyapatite nanocomposite coatings for bone regeneration. Biochem Eng J 98:29-37. https://doi.org/10.1016/j. bej.2015.02.026

46. Nie L, Chen D, Suo J, Zou P, Feng S, Yang Q, Yang S, Ye S (2012) Physicochemical characterization and biocompatibility in vitro of biphasic calcium phosphate/polyvinyl alcohol scaffolds prepared by freeze-drying method for bone tissue engineering 
applications. Colloid Surface B 100:169-176. https://doi. org/10.1016/j.colsurfb.2012.04.046

47. Sopyan I, Mel M, Ramesh S, Khalid KA (2007) Porous hydroxyapatite for artificial bone applications. Sci Technol Adv Mater 8:116123. https://doi.org/10.1016/j.stam.2006.11.017

48. Ahn C, Liang X, Cai S (2015) Inhomogeneous stretch induced patterning of molecular orientation in liquid crystal elastomers. Extreme Mech Lett 5:30-36. https://doi.org/10.1016/j. eml.2015.09.007

49. Wang Z, Fan W, He Q, Wang Y, Liang X, Cai S (2017) A simple and robust way towards reversible mechanochromism: using liquid crystal elastomer as a mask. Extreme Mech Lett 11:42-48. https ://doi.org/10.1016/j.eml.2016.11.015

50. Sheng Y, Tang X, Peng E, Xue J (2013) Graphene oxide based fluorescent nanocomposites for cellular imaging. J Mater Chem B 1:512-521. https://doi.org/10.1039/c2tb00123c

51. Nie W, Peng C, Zhou X, Chen L, Wang W, Zhang Y, Ma PX, He C (2017) Three-dimensional porous scaffold by self-assembly of reduced graphene oxide and nano-hydroxyapatite composites for bone tissue engineering. Carbon 116:325-337. https://doi. org/10.1016/j.carbon.2017.02.013

52. Wan Y, Chen X, Xiong G, Guo R, Luo H (2014) Synthesis and characterization of three-dimensional porous graphene oxide/sodium alginate scaffolds with enhanced mechanical properties. Mater Express 4:429-434. https://doi.org/10.1166/ mex.2014.1188

53. Fei Y, Li Y, Han S, Ma J (2016) Adsorptive removal of ciprofloxacin by sodium alginate/graphene oxide composite beads from aqueous solution. J Colloid Interface Sci 484:196-204. https:// doi.org/10.1016/j.jcis.2016.08.068

54. He Y, Zhang N, Gong Q, Qiu H, Wang W, Liu Y, Gao J (2012) Alginate/graphene oxide fibers with enhanced mechanical strength prepared by wet spinning. Carbohydr Polym 88:1100-1108. https://doi.org/10.1016/j.carbpol.2012.01.071

55. Jiao C, Xiong J, Tao J, Xu S, Zhang D, Lin H, Chen Y (2016) Sodium alginate/graphene oxide aerogel with enhanced strength-toughness and its heavy metal adsorption study. Int J Biol Macromol 83:133-141. https://doi.org/10.1016/j.ijbio mac.2015.11.061

56. Shuai C, Feng P, Gao C, Shuai X, Xiao T, Peng S (2015) Graphene oxide reinforced poly(vinyl alcohol): nanocomposite scaffolds for tissue engineering applications. RSC Adv 5:25416-25423. https://doi.org/10.1039/c4ra16702c

57. Loh QL, Choong C (2013) Three-dimensional scaffolds for tissue engineering applications: role of porosity and pore size. Tissue Eng B Rev 19:485-502. https://doi.org/10.1089/ten. teb.2012.0437

58. Arabnejad S, Burnett Johnston R, Pura JA, Singh B, Tanzer M, Pasini D (2016) High-strength porous biomaterials for bone replacement: a strategy to assess the interplay between cell morphology, mechanical properties, bone ingrowth and manufacturing constraints. Acta Biomater 30:345-356. https://doi. org/10.1016/j.actbio.2015.10.048

59. Rajesh R, Ravichandran YD (2015) Development of new graphene oxide incorporated tricomponent scaffolds with polysaccharides and hydroxyapatite and study of their osteoconductivity on MG-63 cell line for bone tissue engineering. RSC Adv 5:41135-41143. https://doi.org/10.1039/c5ra07015e

60. Yu P, Bao RY, Shi XJ, Yang W, Yang MB (2017) Self-assembled high-strength hydroxyapatite/graphene oxide/chitosan composite hydrogel for bone tissue engineering. Carbohydr Polym 155:507-515. https://doi.org/10.1016/j.carbpol.2016.09.001

61. Yang D, Yu K, Ai Y, Zhen H, Nie J, Kennedy JF (2011) The mineralization of electrospun chitosan/poly(vinyl alcohol) nanofibrous membranes. Carbohydr Polym 84:990-996. https://doi. org/10.1016/j.carbpol.2010.12.057

62. Bertolo A, Mehr M, Janner-Jametti T, Graumann U, Aebli N, Baur M, Ferguson SJ, Stoyanov JV (2016) An in vitro expansion score for tissue-engineering applications with human bone marrowderived mesenchymal stem cells. J Tissue Eng Regen Med 10:149-161. https://doi.org/10.1002/term.1734

63. Wang H, Li Y, Zuo Y, Li J, Ma S, Cheng L (2007) Biocompatibility and osteogenesis of biomimetic nano-hydroxyapatite/polyamide composite scaffolds for bone tissue engineering. Biomaterials 28:3338-3348. https://doi.org/10.1016/j.biomateria Is.2007.04.014

Publisher's Note Springer Nature remains neutral with regard to jurisdictional claims in published maps and institutional affiliations. 